\title{
Effect of Beauty-Related Emotional Intelligence on Self-Elasticity and Subjective WellBeing
}

Yi-Ju Yeo ${ }^{1}$, Eun-Jun Park ${ }^{2 \star}$

${ }^{1}$ Department of Beauty Design, Shin Ansan University, Ansan-si, Gyeonggi-do, Korea

${ }^{2}$ Department of Hair and Makeup Design, College of Beauty Art, Seokyeong University, Seoul, Korea

"Corresponding author: Eun-Jun Park, Department of Hair and Makeup Design, College of Beauty Art, Seokyeong University, 124 Seogyeong-ro, Seongbuk-gu, Seoul 02713, Korea

Tel.: +82 29407846

Email: ayamdream@hanmail.net

\section{Received July 24, 2020}

Revised September 04, 2020

Accepted September 07, 2020

Published September 30, 2020

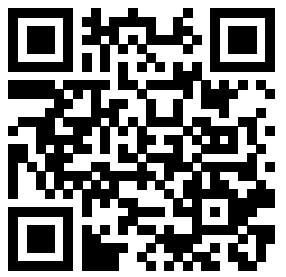

\begin{abstract}
Purpose: This study examined the effect of emotional intelligence on the selfelasticity of beauty-related international students, and it analyzes the effect of emotional intelligence on subjective well-being, highlighting the importance of educational institutions, due to the recent globalization of beauty education resulting from K-beauty. The goal was to propose a way to increase self-elasticity and subjective well-being through emotional intelligence. Methods: SPSS 22.0 was used to analyze the frequency, reliability, factor analysis, and regression analysis of 253 copies of data collected through a questionnaire given to beauty-related international students. Results: It was found that the emotional intelligence of international students related to beauty had a significant effect on self-elasticity and subjective well-being, and the hypothesis was partially adopted. It was also found that the emotional intelligence's empathy and thought-promoting abilities had a great influence. Conclusion: First, parents and teachers who teach international students should be provided with materials to recognize and guide the importance of the students' emotional characteristics. Second, schools should provide various programs to improve emotional intelligence. Third, counseling programs for international students should be developed and implemented. As a result, it is necessary to positively raise the social perception of studying abroad and to make students proud.
\end{abstract}

Keywords: Beauty related, Foreign student, Emotional intelligence, Self-elasticity, Subjective well-being

\section{Introduction}

우리나라의 미용산업은 한국의 유명 연예인들의 이미지를 추구하 는 $\mathrm{K}$-뷰티와 함께 발전해왔다. $\mathrm{K}$-뷰티는 한류열풍에 힘입어 외국 인 유학생의 꾸준한 증가를 만들어 냈고, 우리나라 미용기술의 뛰어 남을 세계적으로 알리는 계기가 되었다.

한국 브랜드 화장품을 포함하여 헤어, 메이크업, 피부관리 등에 대한 관심도가 증가하면서 해외 미용시장에서 한국 뷰티시장과 관 련된 미용 전문인재에 대한 요구가 증가하였고(Lee \& Xu, 2018), 그로 인해 해외의 미용관련 학생들은 한국의 기술을 배워 우수한 인 재로 성장하고자 한국유학을 선택하게 되었다(Kim et al., 2020). 현재 유학생들은 14만명 이상으로 보고되고 있는데(Jiang \& Park, 2020), 2003년에 1만명이 되지 않았던 현실을 고려하면 폭발적인
증가라고 할 수 있다(Lee, 2012).

이렇듯 외국인 유학생이 늘어남에 따라 이들이 대학생활을 원활 하게 하기 위한 요인들이 중요시되고 있다. 성공적인 대학생활과 사회적응을 위한 중요한 요인에는 여러 가지가 있지만 유학생활에 서 인지적, 사회적, 정서적 문제 해결을 할 수 있도록 하는 기본 능 력의 총칭인 정서지능은 매우 중요한 요인이라고 할 수 있다(Son \& Choi, 2011).

정서지능은 자신의 정서를 인식하고 표현하는 능력, 적절히 조절 하여 활용하는 능력, 타인의 정서를 파악하고 공감하는 능력으로 건 강한 사회적 관계를 형성하는데 직접적인 영향을 미치는 것으로 보 고되고 있다(Woo \& Choi, 2002). 또한 원활한 대인관계와 적응력을 높이기 위해 정서지능이 중요한 변인이며(Park, 2010), 정신건강의 향상, 인간관계의 질, 다양한 생활환경에서의 적응 등을 이해하고 
예측하는데 중요한 변인으로 인식되고 있어(Ciarrochi \& QuartlyScott, 2006) 연구의 필요성이 제기된다.

정서지능에 영향을 받는 중요한 변인으로 자아탄력성을 꼽을 수 있는데, 자아탄력성이란 구체적인 상황에 따라 자아 통제를 강화하 거나 완화시키는 뛰어난 대응능력이자, 자아의 동기조절과 인지능 력 등을 포함하는 종합적인 개념으로(Lee \& Xu, 2018), 정서지능과 밀접한 연관성을 갖는다.

한편, 타국생활에 적응해야 하는 유학생들에게 삶의 궁극적 목표 인 행복, 삶의 만족도, 즉, 주관적 안녕감은 교육을 통해 높여야 할 필수적인 요인으로(Yeo et al., 2015), 주관적 안녕감을 높이기 위해 자아탄력성을 증진시킬 필요성이 있다. 이는 개인이 자신의 삶에 대 해 만족스럽게 여기는 주관적 심리상태로 인지적 안녕감인 삶의 만 족으로 이루어지기 때문이다(Kim \& Lee, 2016).

관련된 선행연구를 살펴보면, Paek \& Yoo (2017)는 정서지능이 자아탄력성에 유의한 영향을 미치며, 매우 밀접한 연관성이 있음을 확인하였고, Bonanno et al. (2007)은 긍정적 정서는 자아탄력성을 강화 시킴으로써 스트레스를 효율적으로 극복할 수 있도록 도와준 다고 하였으며, Lee \& Ko (2018)은 보육교사의 정서지능이 자아탄 력성에 미치는 영향을 연구하여 두 변인의 영향관계가 유의미함을 실증분석을 통해 확인하였고, Yeo \& Park (2019)은 정서지능과 감 성지능이 조직성과와 직결됨을 밝혔다. O \& Lee (2011)는 어머니와 유아의 정서지능과 심리적 안녕감의 관계에 대해 연구하여 유의미 한 상관관계가 있음을 확인하였고, Lee et al. (2012)은 안녕감이 정 서지능에 미치는 영향을 확인하고 안녕감이 높을수록 배려심이 깊 고 타인과 잘 어울린다고 밝혔다. 또한 Park \& Jeon (2018)은 중년 기 성인의 정서표현성이 주관적 안녕감에 유의미한 영향을 미치고, 정서표현이 높을수록 긍정정서가 높아진다고 하였다.

이렇듯 정서지능과 자아탄력성, 주관적 안녕감은 매우 밀접한 관 계에 있으며, 중요한 주제로 다루어지고 있다. 그러나 미용관련 유 학생에 대한 연구는 미비한 실정이다. 이에 본 연구는 미용관련 유 학생의 정서지능이 자아탄력성에 미치는 영향에 대해 알아보고, 정 서지능이 주관적 안녕감에 미치는 영향을 분석하여, 최근 $\mathrm{K}$-뷰티로 인해 미용교육의 글로벌화로 인한 교육기관의 중요성을 강조하고, 정서지능을 통해 자아탄력성과 주관적 안녕감을 높일 수 있는 방법 을 제안하는 것을 목적으로 하였다. 나아가 미용교육과 교육기관의 발전과 유학생의 유치 및 관리에 필요한 정보를 제공하고자 한다.

\section{Methods}

\section{1. 연구대상 및 자료수집}

본 연구의 조사대상은 미용관련 유학생을 대상으로 설정하였다. 자료의 수집방법으로 자기기입식 설문지법이 사용되었으며, 예비조 사와 본 조사를 통해 연구문제를 해결하는데 필요한 자료가 수집되 었다.

2020년 3월 20일부터 3월 30일까지 총 30부의 예비조사를 통해 측정도구인 설문지의 구성과 내용을 수정 및 보완한 후 본 조사를 실시하였다. 본 조사는 2020년 4월 1일부터 2020년 4월 30일까지 실시되었고 총 260 부의 설문지를 배포하여 수거된 255 부의 설문지 중 분석에 사용되기 불충분하다고 판단되는 2 부의 설문지를 제외한 253 부가 최종 분석 자료로 사용되었다.

\section{2. 측정항목 및 내용}

본 연구는 자료의 수집을 위해 설문지법이 사용되었다. 설문 문항 은 크게 일반적 특성(7), 정서지능(17), 자아탄력성(12), 주관적 안 녕감(11)의 47 문항으로 구성되었으며, 선행연구의 설문문항 및 구 성개념을 인용 및 응용하였다. 본 연구에 사용된 모든 리커트 척도 는 ' 1 :전혀 그렇지 않다'에서 ' 5 :매우 그렇다'까지의 5 점 리커트 척도 가 사용되었다. 설문지의 구체적인 내용은 Table 1 과 같다.

\section{3. 분석방법}

수집한 자료를 분석하여 연구문제를 검정하기 위해 SPSS 22.0 (IBM, USA), analysis of moment structure (AMOS) 21.0 (IBM) 이 사용되었고, 자료의 분석방법은 가설에 맞게 순차적으로 적용되 었으며 다음과 같다.

첫째, 조사대상의 일반적 특성을 알아보기 위해 빈도분석을 하였 다. 둘째, 정서지능, 자아탄력성, 주관적 안녕감의 각 차원 별 타당 성 및 신뢰성 평가를 위해 요인분석을 시행하였고(주성분분석, 베리 멕스 사용), Cronbach's $\alpha$ 을 이용한 신뢰도 분석을 시행하였다. 셋 째, 정서지능이 자아탄력성과 주관적 안녕감에 미치는 영향을 알아 보기 위해 회귀분석을 실시하였다. 회귀분석의 변수 입력은 단계적 방법을 사용하였다.

\section{4. 연구모형 및 연구가설}

Paek \& Yoo (2017)의 연구에서 정서지능과 자아탄력성은 상호관

\section{Table 1. Configuration of a questionnaire}

\begin{tabular}{lll}
\hline Research variables & \multicolumn{1}{c}{ Scale (No. of questions) } & \multicolumn{1}{c}{ Quotation \& applied data } \\
General characteristics & Nominal scale (7) & Park et al., (2020), Organization of researchers \\
Emotional intelligence & 5-point Likert scale (17) & Noh \& Bae (2014), Kim (2009), Shim \& Pu (2013) \\
Self-elasticity & 5-point Likert scale (12) & Park (2017), Lim (2016), Kim et al., (2016) \\
Subjective well-being & 5-point Likert scale (11) & Na \& Eun (2014), Lee \& Lee (2011) \\
\hline
\end{tabular}


련성이 있음을 확인하였다. 자아탄력성이 높은 학생은 적절하게 정 서를 조절하고 감정을 표현하며, 높은 긍정적 정서를 보이는 것으 로 나타났다. 또한 인지적, 사회적으로 유연하게 대처하고, 문제 상 황이 발생하면 포기하지 않고 스스로 상황을 극복하려고 노력하는 특성을 보인다고 하였다. Lee \& Ko (2018)은 보육교사의 정서지능 이 자아탄력성에 정적인 영향을 미치고, 정서지능이 높을수록 자아 탄력성도 높아질 수 있다고 보았다. Cho (2017)의 연구에서도 긍
정적인 정서표현의 빈도가 높은 어머니의 유아들이 대체로 자아탄 력성이 높다는 것을 확인하여 어머니의 정서지능과 유아의 자아탄 력성이 매우 높은 상관관계가 있음을 확인하였다. 또한 Gil \& $\mathrm{Kim}$ (2016)은 정서지능과 심리적 안녕감의 정적 상관관계를 검증하였고, O \& Lee (2011)는 정서지능과 심리적 안녕감의 관계를 연구하여 어 머니의 심리적 안녕감의 하위요인인 자아수용, 긍정적 대인관계, 삶 의 목적, 자율성 등이 정서지능의 하위요인인 자기인식능력, 자기조

Table 2. General characteristics

$(\mathrm{N}=\mathbf{2 5 3}, \%)$

\begin{tabular}{|c|c|c|c|}
\hline \multirow{2}{*}{\multicolumn{2}{|c|}{ Item }} & \multicolumn{2}{|c|}{ Sum } \\
\hline & & Frequency $(\mathrm{N})$ & Percent (\%) \\
\hline \multirow{2}{*}{ Gender } & Male & 32 & 12.6 \\
\hline & Female & 221 & 87.4 \\
\hline \multirow{4}{*}{ Grade } & Grade 1 & 35 & 13.8 \\
\hline & Grade 2 & 45 & 17.8 \\
\hline & Grade 3 & 102 & 40.3 \\
\hline & Grade 4 & 71 & 28.1 \\
\hline \multirow{5}{*}{ Nationality } & China & 211 & 83.4 \\
\hline & Vietnam & 11 & 4.3 \\
\hline & Mongolia & 12 & 4.7 \\
\hline & Myanmar & 5 & 2.0 \\
\hline & Etc. & 14 & 5.6 \\
\hline \multirow{5}{*}{$\begin{array}{l}\text { Period of stay in } \\
\text { Korea }\end{array}$} & Less than 1 year & 11 & 4.3 \\
\hline & 1 to 2 years & 43 & 17.0 \\
\hline & 2 to 3 years & 53 & 20.9 \\
\hline & 3 to 4 years & 91 & 36.1 \\
\hline & 4 years or more & 55 & 21.7 \\
\hline \multirow{6}{*}{$\begin{array}{l}\text { Topic level at time of } \\
\text { admission }\end{array}$} & Beginner 1 & 2 & 0.8 \\
\hline & Beginner 2 & 22 & 8.7 \\
\hline & Intermediate 3 & 89 & 35.2 \\
\hline & Intermediate 4 & 85 & 33.6 \\
\hline & Advanced 5 & 45 & 17.7 \\
\hline & Advanced 6 & 10 & 4.0 \\
\hline \multirow{6}{*}{$\begin{array}{l}\text { Purpose for studying } \\
\text { abroad }\end{array}$} & To learn skills and knowledge & 148 & 58.5 \\
\hline & To get a degree & 25 & 9.9 \\
\hline & To gain international experience & 29 & 11.5 \\
\hline & To experience Korean culture & 20 & 7.9 \\
\hline & To improve Korean language skills & 16 & 6.3 \\
\hline & Etc. & 15 & 5.9 \\
\hline \multirow{7}{*}{$\begin{array}{l}\text { Reasons for current } \\
\text { school selection }\end{array}$} & I have a field of study & 160 & 63.2 \\
\hline & Someone you know introduced you & 36 & 14.2 \\
\hline & Tuition is cheap & 4 & 1.6 \\
\hline & The scholarship system is well established & 22 & 8.7 \\
\hline & The admission requirements and process are simple & 16 & 6.4 \\
\hline & Etc. & 15 & 5.9 \\
\hline & Sum & 253 & 100.0 \\
\hline
\end{tabular}




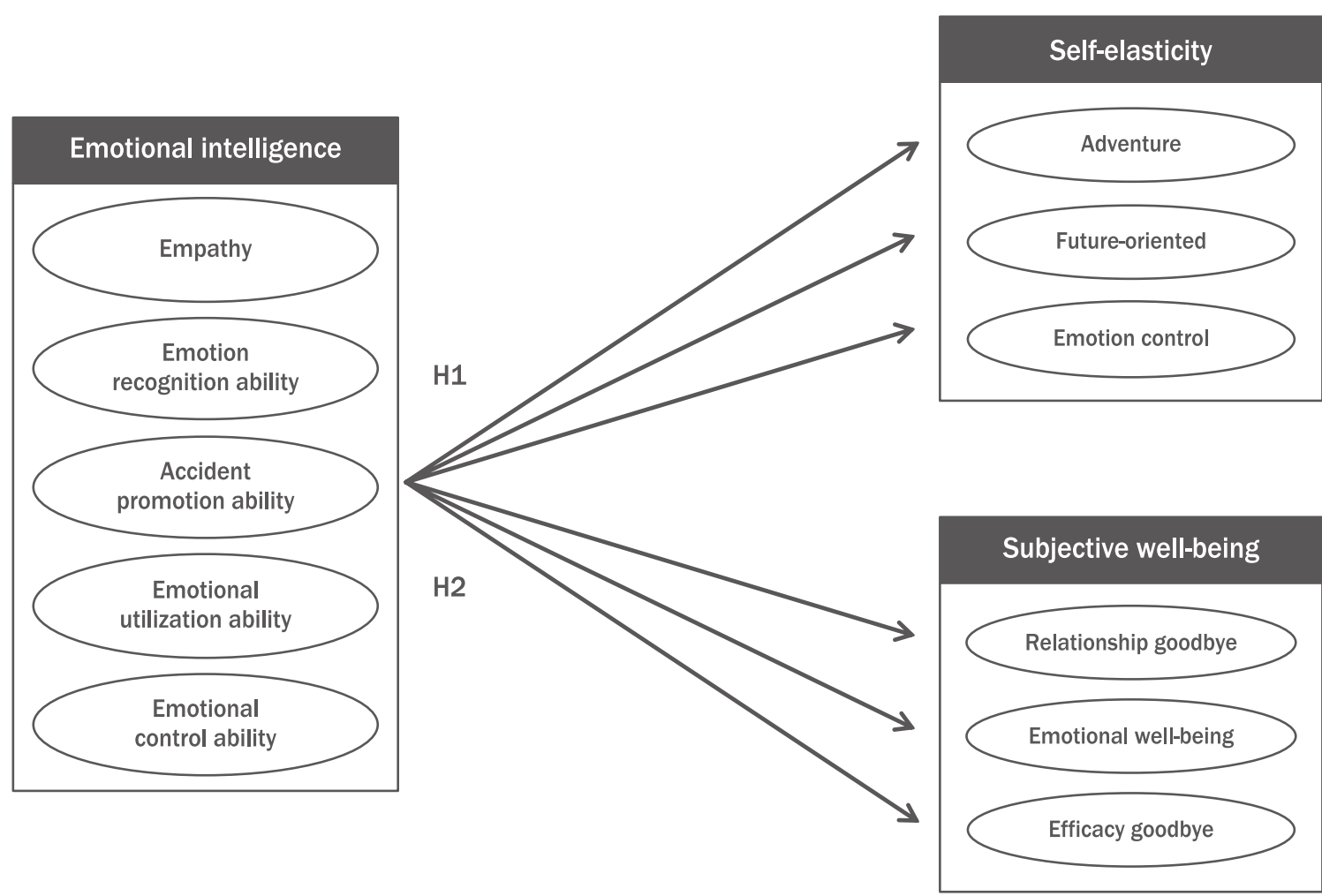

Figure 1. Research model and hypothesis.

Hypothesis 1. Emotional intelligence will positively affect self-elasticity.

Hypothesis 2. Emotional intelligence will positively affect subjective well-being.

절능력, 타인인식능력, 타인조절능력, 정서지능과 밀접한 관계에 있 음을 확인하였다. Lee et al. (2012)은 정서지능을 정서인식, 정서표 현, 감정이입, 정서조절, 정서활용으로 구성하였고, 심리적 안녕감 은 자아수용, 긍정적대인관계, 자율성, 환경통제력, 삶의 목적, 개인 적성장으로 구성하였다. 연구결과 서로 유의미하게 정 $(+)$ 의 영향관 계를 갖는 것으로 나타났다. Na \& Eun (2014)는 주관적 안녕감의 하위요인을 관계 안녕감, 정서 안녕감, 효능 안녕감으로 구성하였 고, 자아탄력성이 주관적 안녕감에 유의미한 영향을 미치는 것을 확 인하였다.

이러한 선행연구를 근거로 본 연구의 가설을 설정하였다. 정서지 능의 구성개념은 O \& Lee (2011)의 연구를 토대로 '감정이입능력', ' 정서인식능력', '사고촉진능력', '정서활용능력', '정서조절능력'으로 구성하였고, 자아탄력성의 구성개념은 Park (2017)의 연구를 토대 로 '모험성', '미래지향', '감정조절'로 구성하였으며, 심리적 안녕감의 구성개념은 Na \& Eun (2014)의 연구를 토대로 '관계 안녕감', '정서 안녕감', '효능 안녕감' 으로 구성하였다. 연구가설에 따른 연구모형 은 다음 Figure 1과 같다.
가설 1. 정서지능이 자아탄력성에 정(+)의 영향을 미칠 것이다. 1-1. 정서지능이 모험성에 정(+)의 영향을 미칠 것이다. 1-2. 정서지능이 미래지향에 정(+)의 영향을 미칠 것이다. $1-3$. 정서지능이 감정조절에 정(+)의 영향을 미칠 것이다.

가설 2. 정서지능이 주관적 안녕감에 정(+)의 영향을 미칠 것이다. 2-1. 정서지능이 관계 안녕감에 정(+)의 영향을 미칠 것이다. 2-2. 정서지능이 정서 안녕감에 정(+)의 영향을 미칠 것이다. 2-3. 정서지능이 효능 안녕감에 정(+)의 영향을 미칠 것이다.

\section{Results and Discussion}

\section{1. 조사대상의 일반적 특성}

조사대상의 일반적 특성을 알아보기 위해 빈도분석을 실시한 결 과는 다음 Table 2 와 같다.

성별은 여자 $87 . \%$, 남자 $12.6 \%$ 로 여자가 높게 나타났다. 학년은 3 학년이 $40.3 \%$ 로 가장 높게 나타났고, 다음은 4학년 $28.1 \%, 2$ 학년 
$17.8 \%, 1$ 학년 $13.8 \%$ 순으로 나타났다. 국적은 중국이 $83.4 \%$ 로 가 장 높게 나타났고, 다음은 몽골 $4.7 \%$, 베트남 $4.3 \%$, 기타 $5.6 \%$, 미 얀마 $2.0 \%$ 순으로 나타났다. 한국체류기간은 3 년에서 4 년 미만이 $36.1 \%$ 로 가장 높게 나타났고, 다음은 4 년 이상 $21.7 \%, 2$ 년에서 3 년 미만 $20.9 \%, 1$ 년에서 2 년 미만 $17.0 \%, 1$ 년 미만 $4.3 \%$ 순으로 나 타났다. 입학당시 한국어능력시험(TOPIK) 등급은 중급 3 이 $35.2 \%$ 로 가장 높게 나타났고, 다음은 중급4 $33.6 \%$, 고급5 17.7\%, 초급2 $8.7 \%$, 고급 $64.0 \%$, 초급1 $0.8 \%$ 순으로 나타났다. 유학 목적은 기술 과 지식을 배우기 위해가 $58.5 \%$ 로 가장 높게 나타났고, 다음은 국 제적인 경험을 쌓기 위해서 $11.5 \%$, 학위를 취득하기 위해서 $9.9 \%$, 한국문화를 체험하기 위해서 $7.9 \%$, 한국어 실력을 올리기 위해서 $6.3 \%$, 기타 $5.9 \%$ 순으로 나타났다. 현재 학교 선택 이유는 원하는 전공분야가 있어서가 $63.2 \%$ 로 가장 높게 나타났고, 다음은 아는 사 람이 소개시켜줘서 $14.2 \%$, 장학금 제도가 잘 되어 있어서 $8.7 \%$, 입
학조건과 입학절차가 간단해서 $6.4 \%$, 기타 $5.9 \%$, 학비가 저렴해서 $1.6 \%$ 순으로 나타났다.

\section{2. 각 변수들의 타당성 및 신뢰도}

1) 정서지능의 타당성 및 신뢰도

정서지능 문항의 타당성을 검증하기 위해 요인분석 한 결과 Table 3 과 같이 다섯 개의 요인이 도출되었다. Bartlett의 단위행렬 점검 결과 $\chi^{2}=1303.800(\mathrm{df}=136, \mathrm{Sig}=0.000), \mathrm{KMO}$ 값 0.764 로 나타났 으며, 공통성은 0.431 이상으로 나타났다.

첫 번째 요인은 '감정이입능력' 요인으로 요인적재값은 $0.562-$ 0.793 로 나타났으며, 고유값은 2.539 , 분산설명비율은 $14.9 \%$ 로 나타났다. 두 번째 요인은 '정서인식능력' 요인으로 요인적재값 은 0.825-0.853로 나타났으며, 고유값은 2.488 , 분산설명비율은 $14.6 \%$ 로 나타났다. 세 번째 요인은 '사고촉진능력' 요인으로 요인적

Table 3. Emotional intelligence validity and reliability

\begin{tabular}{|c|c|c|c|c|c|c|}
\hline & Factor 1 & Factor 2 & Factor 3 & Factor 4 & Factor 5 & \\
\hline Questionnaire & Empathy & $\begin{array}{l}\text { Emotion } \\
\text { recognition } \\
\text { ability }\end{array}$ & $\begin{array}{l}\text { Accident } \\
\text { promotion } \\
\text { ability }\end{array}$ & $\begin{array}{c}\text { Emotional } \\
\text { utilization } \\
\text { ability }\end{array}$ & $\begin{array}{l}\text { Emotional } \\
\text { control ability }\end{array}$ & Commonality \\
\hline I feel good when my friend is praised and likes & 0.793 & 0.168 & 0.139 & 0.037 & 0.086 & 0.685 \\
\hline I am upset when something bad happens to my friend & 0.782 & 0.106 & 0.176 & 0.101 & 0.099 & 0.673 \\
\hline I feel good when I see people who are not even friendly. & 0.684 & 0.048 & 0.191 & -0.065 & 0.219 & 0.559 \\
\hline I tend to myself express well if I like others & 0.562 & 0.355 & -0.071 & 0.224 & -0.044 & 0.498 \\
\hline $\begin{array}{l}\text { I tend to notice whether someone else's emotional } \\
\text { expression or behavior is genuine or not }\end{array}$ & 0.203 & 0.853 & 0.078 & 0.032 & 0.121 & 0.791 \\
\hline I tend to grasp the feelings of unfamiliar people. & 0.181 & 0.841 & 0.087 & 0.061 & 0.019 & 0.752 \\
\hline I tend to be aware of other people's feelings & 0.086 & 0.825 & 0.154 & 0.027 & 0.060 & 0.715 \\
\hline $\begin{array}{l}\text { I have experience solving some difficulties well because } \\
\text { I have a pleasant mood }\end{array}$ & 0.051 & 0.176 & 0.734 & 0.070 & 0.075 & 0.583 \\
\hline $\begin{array}{l}\text { When I choose something, I think about how my } \\
\text { feelings were in similar situations }\end{array}$ & 0.132 & -0.052 & 0.712 & 0.127 & 0.272 & 0.618 \\
\hline $\begin{array}{l}\text { I tend to control my emotions to do what I think is } \\
\text { important }\end{array}$ & 0.352 & 0.209 & 0.706 & 0.059 & -0.067 & 0.674 \\
\hline $\begin{array}{l}\text { I have the thought that emotions and feelings are } \\
\text { sometimes very complex }\end{array}$ & 0.037 & -0.077 & 0.027 & 0.749 & -0.064 & 0.574 \\
\hline I think awe and fear are complex emotions & 0.120 & 0.274 & -0.130 & 0.700 & 0.146 & 0.618 \\
\hline $\begin{array}{l}\text { I try to forget when something bad happens so that it } \\
\text { does not get in the way of other things }\end{array}$ & 0.079 & -0.023 & 0.277 & 0.556 & 0.197 & 0.431 \\
\hline $\begin{array}{l}\text { I think the feeling of anger can change into different } \\
\text { feelings depending on the situation }\end{array}$ & -0.014 & 0.083 & 0.405 & 0.529 & 0.027 & 0.452 \\
\hline I get angry quickly after having a fight with a friend & 0.276 & 0.034 & 0.082 & 0.026 & 0.741 & 0.634 \\
\hline $\begin{array}{l}\text { I don't tend to be annoyed if my work does not go as it } \\
\text { should }\end{array}$ & -0.066 & 0.081 & 0.313 & 0.123 & 0.716 & 0.636 \\
\hline $\begin{array}{l}\text { I would rather feel pitiful and helpless than dirty and } \\
\text { incompetent }\end{array}$ & 0.433 & 0.176 & -0.272 & 0.130 & 0.522 & \\
\hline Eigenvalue & 2.539 & 2.488 & 2.110 & 1.770 & 1.568 & \\
\hline Description variable (\%) & 14.934 & 14.633 & 12.411 & 10.410 & 9.226 & \\
\hline Cumulative variance (\%) & 14.934 & 29.567 & 41.979 & 52.389 & 61.615 & \\
\hline Cronbach's $\alpha$ & 0.731 & 0.843 & 0.702 & 0.583 & 0.544 & \\
\hline
\end{tabular}


재값은 0.706-0.734로 나타났으며, 고유값은 2.110 , 분산설명비율 은 $12.4 \%$ 로 나타났다. 네 번째 요인은 '정서활용능력' 요인으로 요인 적재값은 0.529-0.749로 나타났으며, 고유값은 1.770 , 분산설명비 율은 $10.4 \%$ 로 나타났다. 다섯 번째 요인은 '정서조절능력' 요인으로 요인적재값은 $0.522-0.741$ 로 나타났으며, 고유값은 1.568 , 분산설
명비율은 $9.2 \%$ 로 나타났다.

요인분석 결과 도출된 다섯 개의 요인이 전체 분산의 $61.6 \%$ 이상 설명되고 있는 것으로 나타났다.

각 요인들의 신뢰도 검증 결과, 신뢰도 계수인 Cronbach's $\alpha$ 는 0.544-0.843로 나타나, 신뢰성에는 문제가 없는 것으로 나타났다.

Table 4. Validity and reliability of self-elasticity

\begin{tabular}{|c|c|c|c|c|}
\hline \multirow[b]{2}{*}{ Questionnaire } & Factor 1 & Factor 2 & Factor 3 & \multirow[b]{2}{*}{ Commonality } \\
\hline & Adventure & $\begin{array}{c}\text { Future- } \\
\text { oriented }\end{array}$ & $\begin{array}{c}\text { Emotion } \\
\text { control }\end{array}$ & \\
\hline I am very interested & 0.878 & 0.012 & -0.074 & 0.777 \\
\hline I like something new or unique & 0.824 & 0.132 & -0.052 & 0.699 \\
\hline I tend to know a variety of things & 0.766 & 0.145 & 0.251 & 0.671 \\
\hline I like to be challenged in different experiences & 0.641 & 0.251 & -0.064 & 0.478 \\
\hline Even if I have difficulties, I think it's a valuable thing in life & 0.607 & 0.023 & 0.373 & 0.509 \\
\hline I have goals for the future & -0.043 & 0.812 & -0.018 & 0.661 \\
\hline I think the future is bright & 0.107 & 0.807 & 0.155 & 0.687 \\
\hline I am working on future goals & 0.221 & 0.801 & 0.018 & 0.691 \\
\hline I have hope for the future & 0.241 & 0.774 & 0.223 & 0.706 \\
\hline I can remain calm even in difficult situations & -0.016 & 0.165 & 0.793 & 0.656 \\
\hline I am very patient & -0.008 & -0.080 & 0.739 & 0.553 \\
\hline I am in control of my feelings & 0.184 & 0.337 & 0.554 & 0.454 \\
\hline Eigenvalue & 2.972 & 2.799 & 1.772 & \\
\hline Description variable (\%) & 24.768 & 23.327 & 14.766 & \\
\hline Cumulative variance (\%) & 24.768 & 48.095 & 62.860 & \\
\hline Cronbach's $\alpha$ & 0.814 & 0.833 & 0.570 & \\
\hline
\end{tabular}

Table 5. Validity and reliability of subjective well-being

\begin{tabular}{|c|c|c|c|c|}
\hline \multirow[b]{2}{*}{ Questionnaire } & Factor 1 & Factor 2 & Factor 3 & \multirow[b]{2}{*}{ Commonality } \\
\hline & $\begin{array}{l}\text { Relationship } \\
\text { goodbye }\end{array}$ & $\begin{array}{l}\text { Emotional } \\
\text { well-being }\end{array}$ & $\begin{array}{l}\text { Efficacy } \\
\text { goodbye }\end{array}$ & \\
\hline There are people who know what they are feeling & 0.909 & 0.160 & 0.073 & 0.857 \\
\hline Some people have had long lasting relationships & 0.877 & 0.165 & 0.020 & 0.797 \\
\hline I have people to talk deeply about & 0.811 & 0.126 & 0.124 & 0.689 \\
\hline There are people who can help me in difficult times & 0.705 & 0.029 & 0.312 & 0.596 \\
\hline There are people who can stay together & 0.698 & 0.140 & 0.168 & 0.536 \\
\hline I feel joy in life & 0.154 & 0.894 & 0.066 & 0.827 \\
\hline I feel comfortable in life & 0.167 & 0.842 & 0.144 & 0.758 \\
\hline I feel pleasure in life & 0.130 & 0.781 & 0.339 & 0.742 \\
\hline I can confidently do important things myself & 0.140 & 0.168 & 0.858 & 0.785 \\
\hline I can trust my own abilities & 0.051 & 0.194 & 0.846 & 0.756 \\
\hline I can solve difficult tasks well & 0.258 & 0.107 & 0.668 & 0.524 \\
\hline Eigenvalue & 3.396 & 2.285 & 2.185 & \\
\hline Description variable (\%) & 30.874 & 20.770 & 19.868 & \\
\hline Cumulative variance (\%) & 30.874 & 51.644 & 71.512 & \\
\hline Cronbach's $\alpha$ & 0.877 & 0.839 & 0.771 & \\
\hline
\end{tabular}


2) 자아탄력성의 타당성 및 신뢰도

자아탄력성 문항의 타당성을 검증하기 위해 요인분석 한 결과 Table 4 와 같이 세 개의 요인이 도출되었다. Bartlett의 단위행렬 점 검 결과 $\chi^{2}=1295.415(\mathrm{df}=66, \mathrm{Sig}=0.000), \mathrm{KMO}$ 값 0.713 로 나타 났으며, 공통성은 0.454 이상으로 나타났다.

첫 번째 요인은 '모험성' 요인으로 요인적재값은 0.607-0.878로 나타났으며, 고유값은 2.972 , 분산설명비율은 $24.7 \%$ 로 나타났다. 두 번째 요인은 '미래지향' 요인으로 요인적재값은 0.774-0.812로 나타났으며, 고유값은 2.799, 분산설명비율은 $23.3 \%$ 로 나타났다. 세 번째 요인은 '감정조절' 요인으로 요인적재값은 0.554-0.793로 나타났으며, 고유값은 1.772 , 분산설명비율은 $14.7 \%$ 로 나타났다.

요인분석 결과 도출된 세 개의 요인이 전체 분산의 $62.8 \%$ 이상 설 명되고 있는 것으로 나타났다.

각 요인들의 신뢰도 검증 결과, 신뢰도 계수인 Cronbach's $\alpha$ 는 0.570-0.833로 나타나, 신뢰성에는 문제가 없는 것으로 나타났다.

\section{3) 주관적 안녕감의 타당성 및 신뢰도}

주관적 안녕감 문항의 타당성을 검증하기 위해 요인분석 한 결과 Table 5 와 같이 세 개의 요인이 도출되었다. Bartlett의 단위행렬 점 검 결과 $\chi^{2}=1524.107(\mathrm{df}=55, \mathrm{Sig}=0.000), \mathrm{KMO}$ 값 0.800로 나타 났으며, 공통성은 0.524 이상으로 나타났다.

첫 번째 요인은 '관계 안녕감' 요인으로 요인적재값은 0.698-
0.909로 나타났으며, 고유값은 3.396, 분산설명비율은 $30.8 \%$ 로 나타났다. 두 번째 요인은 '정서 안녕감' 요인으로 요인적재값 은 0.781-0.894로 나타났으며, 고유값은 2.285 , 분산설명비율은 $20.7 \%$ 로 나타났다. 세 번째 요인은 '효능 안녕감' 요인으로 요인적재 값은 $0.668-0.858$ 로 나타났으며, 고유값은 2.185 , 분산설명비율은 $19.8 \%$ 로 나타났다.

요인분석 결과 도출된 세 개의 요인이 전체 분산의 $71.5 \%$ 이상 설 명되고 있는 것으로 나타났다.

각 요인들의 신뢰도 검증 결과, 신뢰도 계수인 Cronbach's $\alpha$ 는 0.771-0.877로 나타나, 신뢰성에는 문제가 없는 것으로 나타났다.

\section{3. 가설의 검증}

1) 가설 1. 정서지능이 자아탄력성에 미치는 영향

정서지능이 자아탄력성에 미치는 영향에 대한 회귀분석 결과는 Table 6과 같다.

자아탄력성의 하위요인인 모험성은 정서지능의 감정이입능력, 사 고촉진능력, 정서활용능력, 정서인식능력 요인이 유의미하게 정(+) 적으로 영향을 미치는 것으로 나타났고, $18.5 \%$ 의 설명력을 갖는 것 으로 나타났다. 이는 정서지능의 감정이입능력, 사고촉진능력, 정서 활용능력, 정서인식능력 변수가 높아질수록 모험성도 높아지고 있 음을 의미한다. 변수의 영향력을 살펴보면 감정이입능력 $\beta=0.277$, 사고촉진능력 $\beta=0.245$, 정서활용능력 $\beta=0.220$, 정서인식능력

Table 6. Effects of emotional intelligence on self-elasticity

\begin{tabular}{|c|c|c|c|c|c|c|}
\hline $\begin{array}{l}\text { Dependent variable } \\
\text { (Self-elasticity) }\end{array}$ & $\begin{array}{l}\text { Independent variable } \\
\text { (Emotional intelligence) }\end{array}$ & B & SE B & $\beta$ & $t$ & $p$ \\
\hline \multirow{5}{*}{ Adventure } & (a constant) & 0.000 & 0.057 & & 0.000 & 1.000 \\
\hline & Empathy & 0.277 & 0.057 & 0.277 & $4.878^{* * *}$ & 0.000 \\
\hline & Accident promotion ability & 0.245 & 0.057 & 0.245 & $4.308^{* * *}$ & 0.000 \\
\hline & Emotional utilization ability & 0.220 & 0.057 & 0.220 & $3.870^{* * *}$ & 0.000 \\
\hline & Emotion recognition ability & 0.113 & 0.057 & 0.113 & $1.978^{*}$ & 0.049 \\
\hline \multicolumn{7}{|c|}{ adj $\mathrm{R}^{2}=0.185 ; F=15.311 ; p=0.000$} \\
\hline \multirow{5}{*}{ Future-oriented } & (a constant) & 0.000 & 0.057 & & 0.000 & 1.000 \\
\hline & Emotion recognition ability & 0.286 & 0.057 & 0.286 & $4.988^{* * *}$ & 0.000 \\
\hline & Empathy & 0.208 & 0.057 & 0.208 & $3.627^{* * *}$ & 0.000 \\
\hline & Emotional control ability & 0.177 & 0.057 & 0.177 & $3.092^{* *}$ & 0.002 \\
\hline & Accident promotion ability & 0.162 & 0.057 & 0.162 & $2.827^{* *}$ & 0.005 \\
\hline \multicolumn{7}{|c|}{$\operatorname{adj} \mathrm{R}^{2}=0.170 ; F=13.897 ; p=0.000$} \\
\hline \multirow{4}{*}{ Emotion control } & (a constant) & 0.000 & 0.058 & & 0.000 & 1.000 \\
\hline & Accident promotion ability & 0.239 & 0.058 & 0.239 & $4.109^{* * *}$ & 0.000 \\
\hline & Emotional utilization ability & 0.230 & 0.058 & 0.230 & $3.944^{* * *}$ & 0.000 \\
\hline & Emotional control ability & 0.211 & 0.058 & 0.211 & $3.629^{* * *}$ & 0.000 \\
\hline \multicolumn{7}{|c|}{ adj $\mathrm{R}^{2}=0.145 ; F=15.202 ; p=0.000$} \\
\hline
\end{tabular}

$\mathrm{B}$, unstandardized coefficient; $\beta$, standardized coefficient; $t$, $t$-value; $\mathrm{R}^{2}$, correlation coefficient; Modified $\mathrm{R}^{2}$, Modified correlation coefficient; VIF, variance inflation factor; $F, F$-value; RD, relative deprivation; PI, personal identification; SI, social identification; ${ }^{*} p<0.05 ;{ }^{* *} p<0.01 ;{ }^{* * *} p<0.001$. 
$\beta=0.113$ 순으로 크게 영향을 미치는 것으로 나타났다.

자아탄력성의 하위요인인 미래지향은 정서지능의 정서인식능력, 감정이입능력, 정서조절능력, 사고촉진능력 요인이 유의미하게 정 (+)적으로 영향을 미치는 것으로 나타났고, $17.0 \%$ 의 설명력을 갖 는 것으로 나타났다. 이는 정서지능의 정서인식능력, 감정이입능 력, 정서조절능력, 사고촉진능력 변수가 높아질수록 미래지향도 높 아지고 있음을 의미한다. 변수의 영향력을 살펴보면 정서인식능력 $\beta=0.286$, 감정이입능력 $\beta=0.208$, 정서조절능력 $\beta=0.177$, 사고촉진 능력 $\beta=0.162$ 순으로 크게 영향을 미치는 것으로 나타났다.

자아탄력성의 하위요인인 감정조절은 정서지능의 사고촉진능력, 정서활용능력, 정서조절능력 요인이 유의미하게 정 $(+)$ 적으로 영향을 미치는 것으로 나타났고, $14.5 \%$ 의 설명력을 갖는 것으로 나타났다. 이는 정서지능의 사고촉진능력, 정서활용능력, 정서조절능력 변수가 높아질수록 감정조절도 높아지고 있음을 의미한다. 변수의 영향력을 살펴보면 사고촉진능력 $\beta=0.239$, 정서활용능력 $\beta=0.230$, 정서조절 능력 $\beta=0.211$ 순으로 크게 영향을 미치는 것으로 나타났다.

따라서 가설 1 은 부분채택 되었다.

2) 가설 2. 정서지능이 주관적 안녕감에 미치는 영향

정서지능이 주관적 안녕감에 미치는 영향에 대한 회귀분석 결과는 Table 7과 같다.

주관적 안녕감의 하위요인인 관계 안녕감은 정서지능의 정서조 절능력, 감정이입능력, 정서활용능력 요인이 유의미하게 정(+)적으
로 영향을 미치는 것으로 나타났고, $17.7 \%$ 의 설명력을 갖는 것으로 나타났다. 이는 정서지능의 정서조절능력, 감정이입능력, 정서활용 능력 변수가 높아질수록 관계 안녕감도 높아지고 있음을 의미한다. 변수의 영향력을 살펴보면 정서조절능력 $\beta=0.347$, 감정이입능력 $\beta=0.212$, 정서활용능력 $\beta=0.148$ 순으로 크게 영향을 미치는 것으로 나타났다.

주관적 안녕감의 하위요인인 정서 안녕감은 정서지능의 정서조 절능력, 감정이입능력, 정서활용능력 요인이 유의미하게 정(+)적으 로 영향을 미치는 것으로 나타났고, $7.9 \%$ 의 설명력을 갖는 것으로 나타났다. 이는 정서지능의 정서조절능력, 감정이입능력, 정서활용 능력 변수가 높아질수록 정서 안녕감도 높아지고 있음을 의미한다. 변수의 영향력을 살펴보면 정서조절능력 $\beta=0.220$, 감정이입능력 $\beta=0.145$, 정서활용능력 $\beta=0.143$ 순으로 크게 영향을 미치는 것으로 나타났다.

주관적 안녕감의 하위요인인 효능 안녕감은 정서지능의 사고촉 진능력, 정서인식능력, 감정이입능력 요인이 유의미하게 정(+)적으 로 영향을 미치는 것으로 나타났고, $19.6 \%$ 의 설명력을 갖는 것으로 나타났다. 이는 정서지능의 사고촉진능력, 정서인식능력, 감정이입 능력 변수가 높아질수록 효능 안녕감도 높아지고 있음을 의미한다. 변수의 영향력을 살펴보면 사고촉진능력 $\beta=0.336$, 정서인식능력 $\beta=0.217$, 감정이입능력 $\beta=0.213$ 순으로 크게 영향을 미치는 것으로 나타났다.

따라서 가설 2 는 부분 채택되었다.

\section{Table 7. The effect of emotional intelligence on subjective well-being}

\begin{tabular}{|c|c|c|c|c|c|c|}
\hline $\begin{array}{l}\text { Dependent variable } \\
\text { (Subjective well-being) }\end{array}$ & $\begin{array}{l}\text { Independent variable } \\
\text { (Emotional intelligence) }\end{array}$ & B & SE B & $\beta$ & $t$ & $p$ \\
\hline \multirow{4}{*}{ Relationship goodbye } & (a constant) & 0.000 & 0.057 & & 0.000 & 1.000 \\
\hline & Emotional control ability & 0.347 & 0.057 & 0.347 & $6.069^{* * *}$ & 0.000 \\
\hline & Empathy & 0.212 & 0.057 & 0.212 & $3.713^{* * *}$ & 0.000 \\
\hline & Emotional utilization ability & 0.148 & 0.057 & 0.148 & $2.584^{* * *}$ & 0.010 \\
\hline \multicolumn{7}{|c|}{$\operatorname{adj} \mathrm{R}^{2}=0.177 ; F=19.099 ; p=0.000$} \\
\hline \multirow{4}{*}{ Emotional well-being } & (a constant) & 0.000 & 0.060 & & 0.000 & 1.000 \\
\hline & Emotional control ability & 0.220 & 0.060 & 0.220 & $3.643^{* * *}$ & 0.000 \\
\hline & Empathy & 0.145 & 0.060 & 0.145 & $2.404^{* * *}$ & 0.017 \\
\hline & Emotional utilization ability & 0.143 & 0.060 & 0.143 & $2.358^{* *}$ & 0.019 \\
\hline \multicolumn{7}{|c|}{ adj $\mathrm{R}^{2}=0.079 ; F=8.203 ; p=0.000$} \\
\hline \multirow{4}{*}{ Efficacy goodbye } & (a constant) & 0.000 & 0.056 & & 0.000 & 1.000 \\
\hline & Accident promotion ability & 0.336 & 0.056 & 0.336 & $5.943^{* * *}$ & 0.000 \\
\hline & Emotion recognition ability & 0.217 & 0.056 & 0.217 & $3.839^{* * *}$ & 0.000 \\
\hline & Empathy & 0.213 & 0.056 & 0.213 & $3.774^{* * *}$ & 0.000 \\
\hline
\end{tabular}

$\mathrm{B}$, unstandardized coefficient; $\beta$, standardized coefficient; $t$, $t$-value; $\mathrm{R}^{2}$, correlation coefficient; Modified $\mathrm{R}^{2}$, Modified correlation coefficient; VIF, variance inflation factor; $F, F$-value; RD, relative deprivation; PI, personal identification; SI, social identification; ${ }^{* *} p<0.01 ;{ }^{* * *} p<0.001$. 


\section{Conclusion}

본 연구는 미용관련 유학생의 정서지능이 자아탄력성에 미치는 영향에 대해 알아보고, 정서지능이 주관적 안녕감에 미치는 영향을 분석하여 정서지능의 중요성을 강조하고 자아탄력성과 주관적 안녕 감을 높일 수 있는 방법을 제안하는 것을 목적으로 하였다. 나아가 미용교육과 교육기관의 발전과 유학생의 유치 및 관리에 필요한 정 보를 제공하고자 한다. 미용관련 유학생을 대상으로 설문지법을 통 해 수집된 자료 253 부는 SPSS 22.0 을 사용하여 빈도분석, 요인분 석, 신뢰도분석, 회귀분석을 실시하였다.

연구결과는 다음과 같았다. 첫째, 조사대상의 일반적 특성을 알아 보기 위해 빈도분석을 실시한 결과 성별은 '여자', 학년은 '3학년'이 가장 높게 나타났고, 국적은 '중국', 체류기간은 '3년에서 4년 미만', 입학 당시 한국어능력시험(TOPIK) 등급은 '중급 3 '이 가장 높게 나타 났으며, 유학목적은 '기술과 지식을 배우기 위해', 현재 학교 선택 이 유는 '원하는 전공분야가 있어서'가 가장 높게 나타났다. 둘째, 정서 지능, 자아탄력성, 주관적 안녕감을 요인분석한 결과, 정서지능은 감정이입능력', '정서인식능력', '사고촉진능력', '정서활용능력', '정서 조절능력'의 다섯 가지 요인이 도출되었고, 자아탄력성은 '모험성', 미래지향', '감정조절'의 세 가지 요인이 도출되었으며, 심리적 안녕 감은 '관계 안녕감', '정서 안녕감', '효능 안녕감' 의 세 가지 요인이 도출되었다. 셋째, 가설검증 결과 정서지능은 자아탄력성과 주관적 안녕감에 부분적으로 유의미한 정(+)의 영향을 미치는 것으로 나타 나 가설은 부분채택 되었다.

이렇듯 정서지능과 자아탄력성, 주관적 안녕감이 유의한 영향관 계임을 확인하였으며, 연구 결과에 따른 시사점은 다음과 같다. 첫 째, 정서지능이 자아탄력성과 주관적 안녕감에 유의한 정(+)의 영향 을 미치는 것으로 나타났으므로, 유학생을 가르치는 부모 및 교사들 에게는 학생들의 정서적 특성의 중요성을 인식하고 지도할 수 있도 록 자료를 제공해 주어야 한다. 수업 전 진단평가를 실시하는 등 학 생들의 성향과 정서지능을 파악할 수 있는 지표를 개발하여 각각의 정서지능에 맞게 차별화하여 지도해야 한다. 둘째, 학교에서는 정 서지능 향상을 위한 다양한 프로그램을 보급해 주어야 한다. 서로의 고충을 함께 공유할 수 있는 동아리 활동이나, 대회 등을 활성화하 여 성취감을 느끼고 포상 등으로 자신의 능력을 보상 받을 수 있도 록 해야 한다. 셋째, 유학생을 위한 상담 프로그램을 개발하여 시행 해야 한다. 타국에서 편안하게 학습에 몰입할 수 있도록 주기적 상 담 지침을 마련하고 주위의 가족, 동료, 교사와 꾸준히 소통하도록 해야 한다. 그로 인해 유학의 사회적 인식을 긍정적으로 끌어올리 고, 학생들이 자부심과 긍지를 가질 수 있도록 해야 한다.

최근 $\mathrm{K}$-뷰티로 인해 미용교육이 글로벌화 되면서 교육기관의 중 요성이 부각되고 있다. 본 연구에서는 미용관련 유학생들의 정서지 능이 자아탄력성과 주관적 안녕감에 미치는 영향에 대해 연구하여, 미용교육과 교육기관의 발전에 기여하는 연구가 될 것으로 사료된
다.

본 연구는 일부 지역의 미용관련 유학생을 대상으로 표본구성을 했으므로 연구 결과를 일반화 시키는데 제한점을 가질 수 있다. 더 욱 광범위한 지역을 대상으로 후속연구가 이루어지길 기대한다.

\section{Acknowledgements}

This research was supported by Seokyeong University in 2020.

\section{Author's contribution}

YJY and EJP Contributed equally to this work. YJY and EJP were designed and surveyed. The collected questionnaire was written by YJY and EJP analyzed using the SPSS program. YJY wrote the manuscript with assistance from EJP

\section{Author details}

Yi-Ju Yeo (Professor), Department of Beauty Design, Shin Ansan University, 135, Shin Ansan Deahak-ro, Danwon-gu, Ansan-si, Gyeonggi-do 15435, Korea; EunJun Park (Professor), Department of Hair and Makeup Design, College of Beauty Art, Seokyeong University, 124 Seogyeong-ro, Seongbuk-gu, Seoul 02713, Korea.

\section{References}

Bonanno GA, Galea S, Bucciarelli A, Vlahov D. What predicts psychological resilience after disaster? The role of demographics, resources, and life stress. Journal of Consulting and Clinical Psychology, 75: 671-682, 2007.

Cho B. A study on relation of young children's ego-resilience on mothers' emotional intelligence and happiness. Journal of Future Early Childhood Education, 24: 91-115, 2017.

Ciarrochi J, Quartly-Scott G. The link between emotional competence and well-being: A longitudinal study. British Journal of Guidance and Counselling, 34: 231-243, 2006.

Gil HJ, Kim SY. Emotional intelligence of early childhood teachers, psychological well-being, social support, and structural relationships between resilience. The Korean Journal of Child Education, 25: 201-220, 2016.

Jiang JY, Park EJ. Mediated effect of self-esteem in the 
relation between leisure activity and college immersion of foreign students of beauty department. Journal of the Korean Society of Cosmetology, 26: 300-310, 2020.

Kim AR, Kim WB, Park EJ. The effect of subjective sense of well-being and appreciation propensity on self-resilience of a foreign student in department of beauty. Journal of the Korean Society of Cosmetology, 26: 219-227, 2020.

Kim HS. The relationship among mothers' clinging, parentingefficacy and preschoolers' emotional intelligence. Journal of Future Early Childhood Education, 16: 203226, 2009.

Kim JU, Lee JH. Mediating effects of self-concept clarity and moderating effects of optimism between parental psychological control and subjective well-being. The Journal of Learner-Centered Curriculum and Instruction, 16: 673-698, 2016.

Kim Y, Yun B, Li JM, Cho HI. The structural relationships among personality, teachers' conflicts, ego-resilience and burnout of secondary school teachers. Korean Journal of Health Psychology, 21: 373-394, 2016.

Lee JA, Xu HY. The mediating effect of ego-resilience on the major satisfaction and career maturity of Chinese international students majoring in beauty. Journal of the Korean Society of Cosmetology, 24: 1256-1267, 2018.

Lee JS, Lee JH. An analysis of the structural relationship among teachers' autonomy, optimism, teaching flow, and subjective well-being. The Journal of Korean Teacher Education, 28: 65-90, 2011.

Lee JY, Ko JU. The study of childcare teacher's emotional intelligence and job performance: focused on mediating effect of ego-resilience. Journal of Early Childhood Education \& Educare Welfare, 22: 185-216, 2018.

Lee KM, Kim YT, Park JH. Influence of psychological wellbeing on highschool student's emotional intelligence and interior-exterior control. Journal of the Korea AcademiaIndustrial cooperation Society, 13: 1027-1034, 2012.

Lee MK. Mobility motivation of Asian students in a Korea's regional university: narratives of $A$ university students on their choice of institution and interpretations. The Korea Educational Review, 18: 177-201, 2012.

Lim JE. Relationship of participation in exercise on elementary schoolers' physical self-efficacy, egoresilience, and satisfaction with school. The Korean Journal of Elementary Physical Education, 21: 103-116,
2016.

$\mathrm{Na} \mathrm{KE}$, Eun HG. The mediating effects of ego-resilience between subjective well-being, peer relationship and stress. The Journal of Korea Elementary Education, 25: 75-91, 2014.

Noh SR, Bae SA. The effects of emotional intelligence and learning flow on college adaptation in undergraduate student. The Journal of Learner-Centered Curriculum and Instruction, 14: 343-362, 2014.

O SY, Lee Hw. The study of the relation between mothers' psychological well-being and children's emotional intelligence. Journal of Psychology and Behavior, 3: 6379, 2011.

Paek HJ, Yoo MH. The analysis of the structural relationship among overexcitability, emotional intelligence, selfresilience and learning flow of gifted students. The Journal of the Korean Society for Gifted and Talented, 16: 23-50, 2017.

Park JE, Jin BU, Park EJ. Knowledge sharing between beauty industry workers based on general individual and organizational characteristics. Asian Journal Beauty and Cosmetology, 18: 79-93, 2020.

Park JW. The effects of self-resilience, social support and selfesteem on life satisfaction among college students from beauty-related departments: focusing on the mediating effects of the quality of life and modulating effects of the academic year. Journal of Basic Design and Art, 18: 195209, 2017.

Park SM, Jeon HS. Emotional expressiveness, savoring beliefs, and well-being in middle-aged adults. Family and Family Therapy, 26: 575-589, 2018.

Park YY. The relationship among young children's preschool adjustment, emotional intelligence and social competence. Early Childhood Education Research and Review, 14: 319-336, 2010.

Shim KH, Pu SS. Impact of emotional intelligence on career commitment and organizational commitment of day-care teachers. The Journal of the Korea Contents Association, 13: 540-549, 2013.

Son MS, Choi AN. Influence of music therapy with traditional children's song upon emotional intelligence and prosocial behavior in pre-school age children. Journal of Emotional \& Behavioral Disorders, 27: 135-157, 2011.

Woo SK, Choi KY. A structural analysis of young children's 
미용관련 유학생의 정서지능이 자아탄력성과 주관적 안녕감에 미치는 영향

emotional competence and related variables. Korean Journal of Child Studies, 23: 15-32, 2002.

Yeo YJ, Park EJ. Emotional Intelligence, customer orientation, and the organizational performance of hair salon workers. Asian Journal of Beauty and Cosmetology, 17:
199-209, 2019.

Yeo YJ, Park JH, Park EJ. Effect relationship between the educator and the educational awareness of the beauty department satisfaction of the majors. Asian Journal of Beauty and Cosmetology, 13:797-804, 2015. 


\section{국문초록}

\section{미용관련 유학생의 정서지능이 자아탄력성과 주관적 안녕감에 미치는 영향}

여이주 ${ }^{1}$, 박은준 $^{2 *}$

${ }^{1}$ 신안산대학교 뷰티디자인과, 경기도 안산시, 한국

${ }^{2}$ 서경대학교 헤어메이크업디자인학과, 서울, 한국

목적: 본 연구는 미용관련 유학생의 정서지능이 자아탄력성에 미치는 영향에 대해 알아보고, 정서지능이 주관적 안녕감에 미치는 영향을 분석하여, 최근 $\mathrm{K}$-뷰티로 인해 미용교육의 글로벌화로 인한 교육기관의 중요성을 강조하고, 정서지능을 통해 자아탄력성 과 주관적 안녕감을 높일 수 있는 방법을 제안하는 것을 목적으로 하였다. 방법: 미용관련 유학생을 대상으로 설문지법을 통해 수집 된 자료 253 부는 SPSS 22.0 을 사용하여 빈도분석, 신뢰도분석, 요인분석, 회귀분석을 실시하였다. 결과: 미용관련 유학생의 정서 지능이 자아탄력성과 주관적 안녕감에 부분적으로 유의미한 영향을 미치는 것으로 나타나, 가설은 부분 채택되었다. 정서지능의 감 정이입능력과 사고촉진능력이 크게 영향을 미치는 것으로 나타났다. 결론: 본 연구 결과에 따른 시사점으로는 첫째, 유학생을 가르 치는 부모 및 교사들에게는 학생들의 정서적 특성의 중요성을 인식하고 지도할 수 있도록 자료를 제공해 주어야 한다. 둘째, 학교에 서는 정서지능 향상을 위한 다양한 프로그램을 보급해 주어야 한다. 셋째, 유학생을 위한 상담 프로그램을 개발하여 시행해야 한다. 그로 인해 유학의 사회적 인식을 긍정적으로 끌어올리고, 학생들이 자부심과 긍지를 가질 수 있도록 해야 할 것이다.

핵심어: 미용, 유학생, 정서지능, 자아탄력성, 주관적 안녕감

본 연구는 2020학년도 서경대학교 교내연구비 지원에 의하여 이루어졌음.

\section{참고문헌}

길현주, 김수영. 유아 교사의 정서 지능, 심리적 안녕감, 사회적지지, 회복탄력성 간의 구조적 관계. 아동교육, 25: 201$220,2016$.

김영숙, 윤분하, 이금희, 조한익. 중등교사의 성격, 교사갈등, 자아탄력성 및 심리적 소진의 구조적 관계. 한국심리학회지 건강, $21: 373-394,2016$.

김종운, 이지혜. 부모의 심리적 통제가 예비초등교사의 주관적 안녕감에 미치는 영향: 자기개념명확성의 매개효과 및 낙관

성의 조절효과. 학습자중심교과교육연구, 16: 673-698, 2016.

김혜순. 어머니의 집착과 양육 효능감 및 유아의 정서지능 간의 관계. 미래유아교육학회지, 16: 203-226, 2009.

나기은, 은혁기. 초등학교 고학년 학생의 주관적 안녕감이 또래관계와 스트레스에 미치는 영향에서 자아탄력성의 매개효 과. 한국초등교육, 25: 75-91, 2014.

노수림, 배성아. 대학생의 정서 지능, 학습몰입, 대학생활적응간의 관계 연구. 학습자중심교과교육연구, 14: $343-362$, 2014.

박선미, 전혜성. 중년기 성인의 향유신념과 주관적 안녕감의 관계에서 정서표현성의 매개효과. 가족과 가족치료, 26 :

575-589, 2018.

박유영. 유아의 유치원 적응력과 정서지능 및 사회적 유능감과의 관계. 유아교육학논집, $14: 319-336,2010$.

강금이, 박은준. 미용학과 유학생의 여가활동과 대학몰입의 관계에서 자아존중감의 매개효과. 한국미용학회지, $26: 300-$ 310, 2020.

김아름, 김우빈 박은준. 미용관련 유학생의 자아탄력성이 주관적 안녕감과 감사성향에 미치는 영향. 한국미용학회지, 26 : 219-227, 2020. 
박정원. 뷰티전공 대학생들의 삶의 만족도에 자아 탄력성, 사회적 지지, 자아 존중감이 미치는 영향: 삶의 질의 매개효과와 학년의 조절효과. 기초조형학연구, 18: 195-209, 2017.

박정은, 진병운, 박은준. 미용서비스업 종사자의 특성에 따른 지식공유. 아시안뷰티화장품학술지, 18: 79-93, 2020.

백혜정, 유미현. 영재학생의 과흥분성, 정서지능, 자아탄력성 및 학습몰입의 구조적 관계 분석. 영재와 영재교육. $16: 23-$ 50, 2017.

손미순, 최애나. 전래동요를 활용한 음악치료가 학령기이전 아동의 정서지능과 친사회적 행동에 미치는 영향. 정서·행동장 애연구, 27: 135-157, 2011.

심경희, 부성숙. 보육교사의 정서지능이 경력몰입 및 조직몰입에 미치는 영향. 한국콘텐츠학회논문지, $13: 540-549$, 2013.

여이주, 박은준. 헤어살롱 종사자의 감성지능과 고객지향성 및 조직성과의 관계. 아시안뷰티화장품학술지, 17: 199-209, 2019.

여이주, 박재홍, 박은준. 전공별 미용학과 대학생의 교육자 인식과 교육 만족도의 영향 관계. 아시안뷰티화장품학술지, 13: 797-804, 2015.

오소영, 이한우. 어머니의 심리적 안녕감과 유아자녀의 정서지능 간의 관계 연구. 심리행동연구, 3: 63-79, 2011.

우수경, 최기영. 유아의 정서능력과 관련변인간 구조 분석. 아동학회지, 23: 15-32, 2002.

이경미, 김영태, 박정환. 고등학생의 심리적 안녕감이 정서지능과 내외통제성에 미치는 영향. 한국산학기술학회지, $13:$ 1027-1034, 2012.

이민경. 지방대학 외국인 유학생들의 유학동기: A대학 아시아 유학생들의 한국유학 선택과 그 의미를 중심으로. 한국교육 학연구, 18: 177-201, 2012.

이재신, 이지혜. 교사의 자율성, 낙관성, 교수몰입과 주관적 안녕감 간의 관계. 한국교원교육연구, 28: $65-90,2011$.

이주영, 고재욱. 보육교사의 정서지능과 직무성과에 관한 연구: 자아탄력성을 매개효과 중심으로. 유아교육·보육복지연 구, 22: 185-216, 2018.

임종은. 운동참여에 따른 초등학생의 신체적 자기효능감, 자아탄력성 및 학교만족도간의 관계. 한국초등체육학회지, $21:$ 103-116, 2016.

조부월. 어머니의 정서지능 및 행복감과 유아의 자아탄력성과의 관계. 미래유아교육학회지, 24: 91-115.

허함옥, 이지안. 미용전공 중국유학생의 전공만족도와 진로성숙도 관계에서 자아탄력성의 매개효과. 한국미용학회지, 24 :

1256-1267, 2018. 


\section{中文摘要}

\section{美容相关专业的留学生的情绪智力对自我弹性和主观幸福感的影响}

余怡周 $^{1}$, 朴銀俊 $^{2 *}$

1新安山大学美容设计科, 京畿道鞍山市, 韩国

2西京大学美容艺术学科, 首尔, 韩国

目的: 探讨情商对与容相关专业的留学生自我弹性的影响, 并分析了情商对主观幸福感的影响, 强调了教育机构 的重要性, 这归因于近来 $K$ 美容使得美容教育的全球化。为的是提出一种通过情商提高自我弹性和主观幸福感的 方法。方法: 使用SPSS 22.0分析通过对与美容相关的国际学生的问卷调查收集的253份数据的频率，可靠性， 因子分析和回归分析。结果: 研究发现, 与美容相关专业的留学生的情商对自我弹性和主观幸福感有显着影响, 并且该假设被部分采纳。还发现，情商的同理心和促进思想的能力有很大的影响。结论：首先，应该向留学生的 父母和老师提供材料, 以认识和指导学生情感特征的重要性。其次, 学校应提供各种计划来提高情商。第三, 应制定和实施针对留学生的辅导计划。因此, 有必要积极提高出国留学的社会意识, 并使学生感到自豪。

关键词: 美容相关, 留学生, 情绪智力, 自我弹性, 主观幸福感 